\title{
The Phenomenology of the Self-Conscious Mind
}

\author{
Robert G. Mays, B.Sc. \\ Suzanne B. Mays \\ Chapel Hill, NC
}

ABSTRACT: The phenomenon of a near-death experiencer's veridical perceptions during the out-of-body experience (OBE) strongly suggests the existence of a self-conscious mind as a "field of consciousness," a region of space where a person's consciousness exists. In the out-of-body state, the mind appears to be nonmaterial and completely independent of the physical body. Ordinarily, though, the self-conscious mind appears as an autonomous entity united with the brain and body. In this united state, the self-conscious mind operates through the mediation of the brain. This view is supported by evidence from neurological phenomena such as subjective antedating of sensory experiences and mental force. This evidence suggests that a nonneural agency induces conscious experience and self-conscious awareness. Phenomena from OBEs, including apparent subtle interactions with physical processes such as light, sound, and physical objects, as well as reported interactions with "in-body" persons, support the view that the self-conscious mind is able to interact in some physical way with the brain. Neurological phenomena such as Benjamin Libet's (1985) delayed awareness of willed action can be reconsidered successfully in light of this view. Such efforts might also prove useful, for example, in explaining phantom limb phenomena.

KEY WORDS: near-death experience; out-of-body experience; mind-body problem; self-conscious mind; veridical perception.

Robert G. Mays, B.Sc., is a retired senior software engineer and Suzanne B. Mays, A.A., is a Certified Music Practitioner (through the Music for Healing and Transition Program) who provides palliative care to hospitalized patients. They have studied neardeath phenomena together for more than 30 years. They are grateful to Mark J. Eisen, M.D., Susan Leonardo, Margaret Heath, James Hoesch, Bruce Kirchoff, Ph.D., Connirae Andreas, and Nancy Willson for their ideas and thoughtful encouragement throughout this research. Reprint requests should be addressed to Mr. Mays at 5622 Brisbane Drive, Chapel Hill, NC 27514; e-mail: mays@ieee.org. 
In the near-death experience (NDE), the apparent locus of an experiencer's self-conscious awareness shifts from being within the body to outside the body. Near-death experiencers frequently find themselves hovering several feet over their physical bodies, watching the efforts to revive them. The shift of consciousness outside the body is a primary characteristic of most NDEs. While outside the body, the near-death experiencer (NDEr) retains the faculties of perception, thought, volition, memory, and feelings, as well as self-awareness, in short, nearly all of the faculties of ordinary consciousness. In a number of cases, the NDE has been shown to have occurred when the body and brain were clinically dead, as in cardiac arrest, that is, with a flatlined electroencephalogram (EEG), no pulse or respiration, and lack of pupil or gag reflexes (van Lommel, van Wees, Meyers, \& Elfferich, 2001). NDErs may still have rich cognitive experiences during the period of complete loss of cortical and brain stem activity, including having veridical perceptions of their immediate physical environs that are later verified.

The fact that self-conscious awareness appears to operate with full mental faculties outside of the body, when the body and brain have ceased to function, contradicts the prevalent view of neuroscience that consciousness can occur only when there is physical brain activity. Yet the NDE appears to be a continuous, seamless experience of the same self who retains a continuity of memory from before the start of the NDE to after the return to the body, like any other significant life experience.

Furthermore, if self-conscious awareness can separate from the body and operate independent of it for a time, then self-conscious awareness probably operates as an autonomous entity as well in the body, although it is intimately united with the body and brain. Thus, the phenomenon of the NDE-related out-of-body experience (OBE) can provide indications of what aspects of consciousness are in fact independent of the brain. Conversely, various "neural correlates of consciousness" can provide indications of how an autonomous conscious entity operates when united with the brain. These two perspectives of consciousness, existing for a time outside the body and, in the usual case, united with it, together argue strongly for the existence and agency of a self-conscious mind.

\section{The OBE Component of the NDE}

The focus of this paper is the OBE component of the NDE, in which the experiencer feels separated from the body but still has veridical 
experiences of the ordinary physical environs. The proportion of NDErs who report an OBE as part of their experience has variously been reported as 75 percent (Greyson \& Stevenson, 1980), 83 percent (Greyson, 1983), and 100 percent (Sabom, 1982). The difference among these different studies may be due to the definition of an OBE. The $\mathrm{OBE}$ is defined as the experience of one's consciousness being separated from one's physical body. In the Weighted Core Experience Index (WCEI) for NDEs, Kenneth Ring (1980) assigned a score of 2 if the individual described a "clear out-of-body experience" and 1 if the individual had a sense of bodily separation without this experience. In his NDE Scale, Bruce Greyson (1983) assigned 2 if the individual clearly left the body and existed outside it and 1 if the individual lost awareness of the body. Our definition is more narrow: a clear sense of separation from the body accompanied by perceptions of the physical world, but not necessarily perceptions of one's body.

A striking example of the clear experience of separation from the body is the case of George Ritchie (1998, pp. 28-30 \& 51; Ritchie \& Sherrill, 1978, pp. 36-41 \& 96-99), which included an unusual OBE with apparent veridical perceptions and a very elaborate NDE. Ritchie, aged 20, a recent recruit in the Army, appeared to die of acute lobar pneumonia in the hospital at Camp Barkeley, located near Abilene, TX, around 3:00 A.M. on December 20, 1943. Ritchie had been unconscious but woke up and found himself sitting on his bed with another person lying in the bed. He remembered his urgent need to get to Richmond for the beginning of his medical training and realized that he had missed the train. Ritchie rushed out of the hospital ward building, passing straight through its metal rear door, and found himself flying rapidly, about 500 feet up, over the frozen landscape. The night was clear and crisp, but he did not feel cold. He saw that he was traveling east, from the position of the North Star to his left in the night sky.

Ritchie came upon a broad river with a long, high bridge and a sizeable city on the far bank. He felt he should stop to get directions to Richmond and "landed" outside a white, red-roofed, all-night café on a corner, with a "Cafe" sign above the door and a blue neon "Pabst Blue Ribbon Beer" sign in the large, right, front window. In trying to speak to a passerby, Ritchie realized that others could not see him. When he leaned on the guy-wire of a telephone pole, his hand passed through it, and he realized that somehow he had been separated from his body and now needed to get back to it. Ritchie rapidly returned to the 
hospital but had difficulty finding his body in the 2300-bed hospital. He finally recognized his body by the ring on his hand. A sheet had been placed over his head, and he realized that he had died. Still, he was awake, thinking, and experiencing, but without a body. Frantically, Ritchie clawed at the sheet to draw it back, but he grasped only air.

Ritchie then encountered a Being of Light whom he understood to be Christ. He had a life review and further extensive experiences in other realms. Ritchie ultimately returned to his body under the sheet, his throat on fire and his chest in pain. An orderly noticed his hand had moved and persuaded the doctor to inject adrenalin directly into the heart muscle, an unusual medical procedure at that time. Ritchie revived and ultimately recovered. In notarized statements some 14 years later, the doctor in charge confirmed that Ritchie had been dead at least eight to nine minutes, and the attending nurse confirmed that Ritchie had been pronounced dead at two different times but had been given the injection into the heart. The nurse confirmed that after Ritchie had recovered, he told her that he had had an unusual, lifechanging experience but did not go into details.

Ten months later, after flunking out of medical training, Ritchie was driving with three Army buddies back to Camp Barkeley to finish basic training. They drove south from Cincinnati and came to Vicksburg where they stayed overnight. Ritchie had never been to Vicksburg before. The next morning, Ritchie recognized how the river flowed next to Vicksburg and, as they drove through the city, he recognized that up the street they would come to the cafe where he had "landed" the previous December. Ritchie sat there in the car in front of the café. He recognized the neon Pabst sign in the window (now out) and the guywire, exactly as they had appeared earlier. The all-night cafe was 524 miles directly due east of the hospital door at Camp Barkeley.

Ritchie's NDE was unusual for the extent and duration of the OBE component and for its apparent veridical perceptions of physical reality. These aspects probably resulted from Ritchie's strong desire not to miss the start of his medical training at the time of his "death." His desire propelled him away from the hospital to a strange city many miles away, whereas most NDE OBEs occur in the general vicinity of the NDEr's body. Paul Edwards (1996) critiqued Ritchie's account and dismissed his recognition of the river and bridge, the city of Vicksburg, and the café as a déjà vu experience to which Ritchie would be prone, to supply the needed rational support for his experience. Edwards 
supplied no justification for this assessment, but his use of this term is incorrectly applied to Ritchie's experience. The standard definition of déjà $v u$, "any subjectively inappropriate impression of familiarity of a present experience with an undefined past" (Brown, 2004, p 12), does not apply, because Ritchie stated that he recognized specific details of the building and the locale from memory of a specific experience, hardly an "impression of familiarity with an undefined past."

In the following three sections, we present a more detailed phenomenology specifically of the OBE component of the NDE.

\section{Continuity of Consciousness with Cessation of Brain Function}

Several prospective studies of cardiac arrest survivors have been conducted that provide an unambiguous model of the NDE during the dying process (Greyson, 2003; Parnia \& Fenwick, 2002; Parnia, Waller, Yeates, \& Fenwick, 2001; Sartori, Badham, \& Fenwick, 2006; Schwaninger, Eisenberg, Schechtman, \& Weiss, 2002; van Lommel et al., 2001). The NDE occurs with reasonable frequency during cardiac arrest, sometimes with an OBE component that includes veridical elements (Sabom, 1982, 1998; van Lommel et al., 2001). The physiology of cardiac function, respiratory function, cerebral electrical activity, and cerebral blood flow following cardiac arrest is well-known and corresponds to the criteria for determination of death: no cardiac output; no spontaneous respiration; and fixed, dilated pupils. Within 10 seconds after an arrest, blood flow to the brain, electrical brain activity, and brain stem function all rapidly cease and the patient loses consciousness. For a period, the patient may be considered clinically dead, even if he or she is subsequently successfully resuscitated. Nevertheless, during the arrest, some patients report vivid, conscious, out-of-body perceptions of themselves and their physical environs that are characteristic of the NDE.

Within the first 10 seconds or so of cardiac arrest, the velocity of blood flow in the middle cerebral artery $\left(V_{\text {mas }}\right)$ drops to zero centimeters per second, and blood pressure drops to less than 20 millimeters of mercury (Clute \& Levy, 1990; de Vries, Bakker, Visser, Diephuis, \& van Huffelen, 1998; Gopalan, Lee, Ikeda, \& Burch, 1999; Parnia \& Fenwick, 2002). $\mathrm{V}_{\text {mca }}$ is a reliable measure of overall cerebral blood flow. Also during the initial 10 seconds or so, the patient's EEG changes first by a short-term increase in alpha frequencies, then a drop in both alpha and beta frequencies, an 
increase in delta frequencies, and finally a decrease in delta frequencies (Visser, Wieneke, van Huffelen, de Vries, \& Bakker, 2001). The EEG then declines to zero or isoelectricity (that is, it "flatlines") within 10 to 20 seconds after the arrest (Clute and Levy, 1990; de Vries et al., 1998; Losasso, Muzzi, Meyer, \& Sharbrough, 1992; Vriens, Bakker, de Vries, Wieneke, \& van Huffelen, 1996). The patient loses consciousness prior to isoelectricity, during the increased delta activity, that is, about 10 seconds after arrest (Aminoff, Scheinman, Griffin, \& Herre, 1988; Brenner, 1997). Also just prior to isoelectricity, the patient may exhibit short muscle spasms and jerking (Brenner, 1997). With the decline of cortical electrical activity, brain stem electrical activity also declines simultaneously to isoelectricity, as observed by monitoring brain stem auditory evoked potentials during induced cardiac arrest in hypothermic circulatory arrest procedures for treatment of cerebral circulatory aneurysms (Spetzler, Hadley, Rigamonti, Carter, Raudzens, Shedd, \& Wilkinson, 1988). Brain stem isoelectricity is also consistent with the observed loss of consciousness and general loss of autonomic function and reflexes associated with brain stem activity: no spontaneous respiration; no pupillary response to light; and no corneal reflex, gag reflex, or cough reflex. Because brain stem electrical activity mirrors cortical electrical activity as a result of the level of cerebral blood flow, it is reasonable to infer that virtually all brain electrical activity ceases in the first 15 seconds, on average, of cardiac arrest.

With the onset of cardiopulmonary resuscitation (CPR), such as chest compressions, defibrillation shock, artificial respiration, and administration of drugs, low level cerebral blood flow (reperfusion) can resume. With reperfusion, the EEG may begin to recover, even before cardiac function is restored (Losasso et al., 1992). EEG recovery follows the pattern of EEG changes at cardiac arrest in reverse order (Brenner, 1997). As the arrest duration increases, EEG recovery time, the time measured from cardiac recovery to return to normal EEG, increases even more. For example, an arrest of 40 seconds duration will result in an EEG recovery time of about an additional 80 seconds (de Vries, Visser, and Bakker, 1997; Vriens et al., 1996). Even after short periods of unconsciousness of 60 to 90 seconds, the patient is usually dazed, slow to respond, or confused for about 30 seconds after regaining consciousness (Aminoff et al., 1988).

If the arrest lasts longer than a threshold of about 37 seconds, when circulation subsequently resumes there is a period of cerebral 
"hyperfusion" during which blood flow and oxygen uptake in the brain are much greater than normal (de Vries et al., 1998; Smith, Levy, Maris, and Chance, 1990). Data for longer periods of cardiac arrest are available from animal experiments. In induced cerebral ischemia in rabbits from 2.5 to 15 minutes, specific regions of the brain develop circulatory defects that inhibit or prevent reperfusion, a phenomenon called "multifocal no-reflow" (Ames, Wright, Kowada, Thurston, and Majno, 1968). The no-reflow defects occur during the arrest and increase in number as the duration of ischemia increases. The defects are probably caused by reduced post-arrest blood pressure, increased blood viscosity, disseminated blood clots, and compression of blood vessels due to swelling (Buunk, van der Hoeven, \& Meinders, 2000). If the defects are too severe, the global hyperfusion and hyperoxia that ensue are not able adequately to reoxygenate the affected regions. Thus, the longer the cerebral ischemia, the larger will be the areas of permanent damage. The regions that were most susceptible to noreflow damage in animal experiments were the striatum, thalamus, and hippocampus, as well as various regions of the cortex (Kågström, Smith, \& Siesjö, 1983). These results are consistent with findings in humans (Fujioka, Nishio, Miyamoto, Hiramatsu, Sakaki, Okuchi, Taoka, \& Fujioka, 2000; Kinney, Korein, Panigrahy, Kikkes, \& Goode, 1994) and are consistent with observed cognitive and memory deficits in cardiac arrest survivors (Dougherty, 1994; Sauvé, Walker, Massa, Winkle, \& Scheinman, 1996).

The usual duration of cardiac arrest is 1 to 2 minutes in cardiac care units (van Lommel, 2006), 5 minutes in nonmonitored hospital wards (Herlitz, Bång, Aune, Ekström, Lundström, \& Holmberg, 2001), and even longer in an out-of-hospital cardiac arrest. In the Dutch prospective study of 344 cardiac arrests (van Lommel et al., 2001), $68 \%$ of the 344 patients were successfully resuscitated in the hospital. Of these, $81 \%$ were resuscitated within 2 minutes of arrest, and $80 \%$ were unconscious less than 5 minutes, and another $13 \%$ were resuscitated within 1 minute of arrest and were unconscious less than 2 minutes. The remaining patients in the study received CPR outside the hospital (usually in an ambulance) or were resuscitated both out of and in the hospital. Of these 110 patients, $80 \%$ were in arrest longer than 2 minutes, and 56\% were unconscious longer than 10 minutes. Overall, $36 \%$ of the 344 patients were unconscious longer than 60 minutes. These statistics are probably typical of cardiac arrest resuscitation in general: The typical in-hospital cardiac arrest 
survivor is in arrest for 1 to 2 minutes and is unconscious 2.5 to 5 minutes. The typical out-of-hospital cardiac arrest survivor is in arrest for about 4 to 10 minutes and is unconscious about 10 to 60 minutes or longer.

From the foregoing description of cardiac arrest physiology, the period of global cerebral isoelectricity typically goes from 15 seconds after the arrest to 5 to 10 seconds after the start of CPR but reverts to isoelectricity when chest compressions are stopped if cardiac function has not restarted. Even with the restart of electrical activity, the EEG does not return to normal for a considerable time after rhythmic delta activity reappears, depending on the length of the arrest (de Vries et al., 1997; Vriens et al., 1996). In a best-case scenario of an arrest of only 40 seconds, the EEG recovery time would be an additional 80 seconds. In longer arrest times, the EEG recovery time and corresponding cognitive functions would be influenced by the multifocal no-reflow effects that occur and would be considerably longer. Similarly, the period of unconsciousness goes from 10 seconds after the arrest to some time after the return of normal EEG, probably followed by a period of dull or confused consciousness. In cardiac arrests of 2 minutes or longer, the duration of unconsciousness is probably most influenced by multifocal no-reflow effects.

During the period of global cerebral isoelectricity and loss of consciousness, some cardiac arrest survivors report vivid NDEs that include OBEs with apparent veridical perceptions of the events of their resuscitations. Their perceptions can place the time of their conscious experience, which can then be correlated with the likely state of their brain function, such as minimal cerebral activity (for example, during CPR or defibrillation) or no cerebral activity (for example, in arrest). Frequently, their veridical perceptions include the onset of the resuscitation efforts (Sabom, 1982, pp. 28-31, 53, 87-113), when global cerebral isoelectricity was very possible.

One example of the apparent continuity of consciousness through a period of complete cessation of cerebral activity was documented by Michael Sabom (1998). Pam Reynolds, age 35, underwent surgery in 1991 for a large basilar artery aneurysm at the base of her brain. The complex procedure involved hypothermic cardiac arrest, which included lowering her body temperature to 60 degrees Fahrenheit, stopping her heart and breathing, and draining the blood from her brain (Spetzler et al., 1988). At this point, Reynolds was in "standstill" and, by all measures, was dead. The aneurysm was then excised, her 
blood and body temperature restored, and her heart and breathing restarted.

Anesthesia was induced at 7:15 a.m., Reynolds's eyes were taped shut, and molded ear plugs were placed in her ears and taped, which emitted 100 decibel clicks at 11 to 33 clicks per second (a deep hum, three to four octaves below middle $\mathrm{C}$, as loud as a jackhammer at two meters). At 8:40 her body was draped, and around 8:45 Reynolds experienced an NDE OBE, as the surgeon began cutting through her skull with a specialized pneumatic surgical saw to access her brain. Her vision in the OBE was more focused and clearer than normal. As she hovered over the surgeon's shoulder, she noticed that the saw resembled an electric toothbrush with a peculiar shape. It used interchangeable blades that were kept in a container resembling a socket wrench case. Reynolds also heard comments from a female doctor about her veins and arteries being too small. Reynolds continued to have a deep NDE involving a tunnel vortex, entering an incredibly bright light, and meeting a number of deceased relatives.

During the time of her NDE, the surgical procedure continued: Blood cooling started at 10:50, and Reynolds's heart was stopped at 11:05. The EEG monitor registered cerebral isoelectricity. Brain stem function, measured by evoked potential electrical activity in response to the 100 decibel clicks, also gradually went to zero. Reynolds was brought to standstill about 11:25 with the blood drained from her body. The surgical excision of the aneurysm was completed, and her blood flow was restarted. At this point, the EEG and brain stem monitors showed resumption of electrical activity. At 12:00 Reynolds's heart was restarted. At 12:32 p.m., the bypass machine was removed, and around 2:00 the surgical wounds were closed. In her NDE, Reynolds was brought back through the tunnel by her deceased uncle and saw her body. She did not want to get back into the body because it looked terrible to her, like a corpse. Nevertheless, with a little push, she reentered her body. When Reynolds came back to her body, she heard the younger surgical assistants playing a particular song in the background.

Later, Sabom verified that Reynolds's perceptions of the surgical saw and of the doctor's comment about her veins were accurate. However, both of these perceptions occurred around 8:45, while Reynolds was under anesthesia but well prior to cortical isoelectricity, which went from about 11:05 until perhaps 11:45. The time of her return to the body can be established as having occurred around the 
time of surgical closure (that is, 2:00), because Reynolds could identify music being played in the background (Sabom, 2007, p. 258). The entire NDE was thus framed at the beginning and end by veridical perceptions and included the period of documented standstill.

In this account, we have a conscious NDE OBE with veridical perceptions during a surgical procedure but not during cerebral isoelectricity. However, the NDE continued with no apparent interruption through an extended period of probably 40 minutes of monitored cortical isoelectricity. Reynolds's account did not indicate a sense at any point of her NDE that her consciousness was diminishing or fading, or that she was being drawn back to her body, except after coming back, when she was "pushed" back into her body. Thus, whereas the veridical perceptions occurred at a point when Reynolds was under anesthesia and, therefore, unconscious, they occurred while there was still some electrical brain activity consistent with anesthesia. Nevertheless, the initial OBE component was part of a continuous conscious experience that spanned a period of about 40 minutes of global cortical isoelectricity. One would expect that Reynolds would have had no experience whatsoever, given that she was anesthetized during the entire time and had no cortical electrical activity during a major portion of the surgery.

Keith Augustine (2007a, 2007b) claimed that Reynolds's experience was more readily attributable to anesthesia awareness: He proposed that Reynolds's anesthesia failed and that she was able to hear the pneumatic saw, inferring its shape and socket wrench case from prior experiences at a dentist's office, and to hear the doctor's comment about the size of her veins and arteries, despite the molded speakers in her ears. He suggested that during standstill, Reynolds slipped into unconsciousness but resumed her anesthesia awareness after rewarming; therefore, she would not have felt any period of unconsciousness. However, Reynolds's experience was not consistent with the typical patient experience of anesthesia awareness, which is characterized by pain, helplessness, terror, paralysis, and postoperative distress (Osterman, Hopper, Heran, Keane, \& van der Kolk, 2001). Augustine's explanation also does not account for Reynolds's failure to notice the brain stem evoked potential tests blasting in her ears. These tests were conducted about 25 times during the procedure: prior to surgical opening; during the bypass, cooling, arrest, and rewarming; and prior to surgical closing. Reynolds could hear the doctor's voice through the coverings in and around her ears but not the 
100 decibel tests directly in her ears. In a study of unconsciousness in 100 patients, Madelaine Lawrence (1997) described 27 cases of "total unconsciousness." In those cases, there was a discontinuity in the subjective experience - that is, experiencing one thing and then experiencing something different, with no transition - with some patients also having a distinct warning of the impending unconscious episode. If Reynolds's experience included a period of unconsciousness, we would expect her account to include a similar discontinuity, and probably also a warning that her consciousness was fading. Reynolds reported neither of these experiences.

In a cardiac arrest with an NDE, even with the onset of global cerebral ischemia and cerebral isoelectricity, the patient appears to experience a continuity of consciousness, generally with a perspective out of the body, looking down. The patient generally experiences no disruption in consciousness (except for the change in perspective) at a time when all electrical brain activity has almost certainly ceased. The patient experiences a lucid, vivid consciousness of the physical environs and still possesses all of the faculties of ordinary consciousness. The patient appears to experience complete continuity of consciousness even when the cerebral electrical activity resumes, until there is a clear transition back to the body, at which point the patient's consciousness continues, now with an in-body perspective, or the patient becomes unconscious and wakes up later. During the entire period of out-of-body consciousness, the patient appears to medical personnel to be completely unresponsive and unconscious.

Thus, the phenomenon of NDEs during cardiac arrest, with veridical out-of-body experiences of the physical environs during the period of global cerebral isoelectricity, challenges the hypothesis that consciousness is entirely dependent on brain function. Under ordinary circumstances this hypothesis is correct, because the loss of electrical brain activity nearly always results in unconsciousness. However, the cases of NDEs during cardiac arrest are notable exceptions which show that, once separated from brain function in an NDE, the patient's consciousness appears to continue in an OBE. Even after brain electrical activity resumes, consciousness continues to operate independently until there is a sense of reuniting with the body. Any interruption in consciousness during the NDE OBE would be evident, because the transitions in losing and then regaining consciousness would be remembered as discontinuities (Lawrence, 1997). Such interruptions are never reported in these NDEs. The patient's 
consciousness functions with all of the attributes of ordinary consciousness, in a continuity of self-conscious experience that spans when the patient was in the body, through the OBE, and back through the time of reuniting with the body. The patient experiences the transitions out of and back into the body as natural, albeit unusual, occurrences and is able to integrate the entire experience in memory.

\section{Veridicality of NDE OBE Perceptions}

The foregoing account of the continuity of consciousness during periods of global cerebral isoelectricity rests on the validity of veridical perceptions during the NDE OBE, because these perceptions establish that the NDE consciousness occurred at a time of global cerebral isoelectricity or, at minimum, profound physical unconsciousness. The evidential value of these perceptions depends on corroborative evidence that the perceptions were real (that is, "veridical") and that they could not have been imagined or mentally constructed at some other time, for example, having been inferred from subliminal sensory awareness during anesthesia, from prior general knowledge, from expectations derived from earlier experiences, from information supplied by others after the fact, from lasting physical aftereffects such as soreness or burns from a defibrillation, or from lucky guesses (Blackmore, 1993).

There are hundreds of accounts of purported veridical NDE OBE perceptions. Usually they are checked by the NDErs themselves soon after the experience. The perceptions are frequently self-verified, as in the case of Ritchie described above, or are verified by asking one other witness, as in "I told the doctor what I saw and he said it happened just that way" (Moody, 1975, pp. 98-100; Moody \& Perry, 1988, pp. 170-172). In some cases, the NDE is reported by the attending physician who provided the verification (Parnia, 2006, p. 77). In some cases, the perceptions were of unusual events occurring in other parts of the hospital (Moody \& Perry, 1988, pp. 18-20).

As a rule, NDE OBE perceptions are found informally to be veridical, that is, they appeared real, were checked with witnesses, and were verified. In contrast, reports that perceptions in an NDE were found to be nonveridical are rare. Janice Holden (2008) reported results of a study of NDEs with purported veridical perception that could not have been the result of normal perception and that was corroborated by the NDEr or others. Of 93 cases, 92 percent appeared 
completely accurate, 6 percent had both accurate and erroneous elements, and less than 1 percent were completely erroneous.

Thus, one would expect that NDE OBE perceptions would be easily proven formally to be veridical. However, in only a few cases have NDE researchers been able to corroborate experiencers' perceptions more thoroughly by checking independently more than one source. Two examples of corroborated veridical NDE perceptions are those of Al Sullivan (Cook, Greyson, \& Stevenson, 1998) and the patient with the nurse peeking around the curtain (Sartori et al., 2006). In the first case, Sullivan, 56 years old, underwent emergency coronary bypass surgery and while unconscious felt himself leave his body. He was able to look down and saw his surgeon "flapping his elbows" as if trying to fly. On regaining consciousness, he related his observation to another physician, who confirmed that the surgeon had this peculiar habit to avoid touching the sterile operating field. Nine years later, the surgeon confirmed that it was his regular habit to point with his elbows, so as not to touch anything until the actual surgery.

In the second case (Sartori et al., 2006), a 60-year-old man recovering from surgery was asked by a physiotherapist to get up and sit in a chair. Within 5 minutes, the patient's blood pressure dropped and his condition deteriorated, including a brief episode of cardiac arrhythmia that reverted spontaneously. He was put back in bed and was deeply unconscious. The physiotherapist was concerned that she had caused the episode and nervously poked her head around the bedside screens from time to time to check on the patient. Upon recovering, the patient immediately reported that he had floated out of his body and could see the doctor and nurses working on him. He also reported that he saw the nervous-looking physiotherapist hiding behind the curtains and poking her head around to check on him. The patient's perceptions were corroborated by Penny Sartori, who was present during the procedure.

In both of these cases, the central veridical perception was an unusual occurrence of a purely visual perception when the patient was unconscious. In both cases, the perception was later independently corroborated, in the latter case within a short time.

Thus, the evidence so far for veridical perception during NDE OBE is abundant, but veridicality has been demonstrated reasonably conclusively in only a few cases (see also the NDEr who saw the nurse opening a glass vial in another room, Moody \& Perry, 1988, pp. 19-20). The lack of full, formal corroboration needs to be balanced 
against the large number of cases of informal verification and the near absence of nonveridical elements in reported NDE OBE perceptions. The cases of informally verified veridical perceptions and those with good corroboration together strongly suggest that the NDEr's experience of viewing events outside of the body are correct and that consciousness operates completely independent of the body during NDE OBE.

\section{Phenomenology of the NDE OBE}

It is important for the present discussion to develop the phenomenology specifically of the NDE OBE in more detail, drawing from various general phenomenological descriptions of the NDE and from individual NDE accounts in the literature.

First, the process of leaving the body is frequently accompanied by a hissing, whirring, or whooshing sound (Moody, 1975, pp. 29-30; Ring, 1980, pp. 94-95) and occasionally by tingling throughout the body (Grey, 1985, p. 48; Ring \& Valarino, 1998, pp. 13-14). There does not appear to be a consistent part of the body through which the nonmaterial body leaves the physical body. A few NDE OBErs observe a thin thread or cord attaching their nonmaterial body to the physical body.

Second, the apparent locus of consciousness shifts from within the physical body to outside and appears to have an independent existence. NDE OBErs can generally perceive their immediate physical surroundings, including their physical bodies, with a perspective some 4 to 8 feet above it, frequently at the ceiling in a corner of the room. There is a complete separation of the self from the physical body, which now generally appears as an "empty shell" (Sabom, 1982, p. 21). A few NDErs observe that their physical body still moves and interacts with the physical world, but they are detached from it (Gibson, 1992, pp. 234-236; Harris \& Bascom, 1990, p. 23; Steiger, 1994, pp. 97-98). There is a continuity of the individual's sense of self and of memory, which continues from being in the body, to out of the body, and then back to the body. The individuals feel themselves to be the same persons throughout the experience.

Third, individuals feel no pain, as in physical bodily pain, even when painful medical procedures are performed on the body (Sabom, 1982, pp. 31,100 ). They have the feeling that they have been freed from the 
body, and they typically report feeling elated at that sense of freedom. They feel weightless and tireless, a general warmth, and completely at peace. However, during hellish types of NDEs, they apparently can experience injury to the nonmaterial "body" and emotional pain (Dovel, 2003, p. 87; Storm, 2000, p. 20).

Fourth, Raymond Moody (1975) found that a large majority of individuals reported they had some sort of nonmaterial body during the NDE (p. 42), although other researchers found a lower percentage: $58 \%$ of individuals (Greyson \& Stevenson, 1980). The "body" has a quality variously described as translucent, "cloud-like," and an "energy pattern" (Serdahely, 1993, p. 88) and as shaped either like the physical body or like a sphere or ovoid (Lundahl \& Widdison, 1997, p. 108; Moody, 1975, pp. 42-50). For other NDErs, their consciousness appears to be a single point or focus.

Fifth, a surprising number of people who had their NDEs during infancy or early childhood report that they were "adults" during their NDEs (Moody \& Perry, 1988, pp. 74-76). Cherie Sutherland (1995, pp. 13-14) characterized the reports of the NDEs of very young, prelinguistic children as quite complex when they were later reported. It appears that most reports of an NDE OBE that was experienced by a neonate or infant describe the experience from an adult perspective, with the NDEr at the time apparently having fully-developed perception and thought, and retaining memory of the experience, similar to having an adult mind in a child's body (Atwater, 1994, pp. $12-13,24-26$; 2003, pp. 8, 64-65, 236-238; 2007, pp. 55-56; Fenwick \& Fenwick, 1995, pp. 183-184; Morse \& Perry, 1990, pp. 40-42; Ring \& Valarino, 1998, pp. 107-112; Serdahely \& Walker, 1990; Sutherland, 1995, pp. 56-57, 82-83, 136-138).

Sixth, existing sensorimotor or structural defects or disabilities such as blindness, deafness, lameness, or missing limbs are absent in most NDErs, but not in all cases (Gibson, 1992, pp. 229-230; 1999, p. 130; Grey, 1985, pp. 87-88; Moody \& Perry, 1988, p. 86). In one study, out of 60 NDErs who reported having a nonmaterial "body," 46 had no preexisting defects, 12 reported their pre-existing defects were absent, and 2 reported such defects were still present (Greyson \& Stevenson, 1980). NDErs with poor vision can see clearly (Ring \& Valarino, 1998, pp. 60-62). NDErs who are blind or visually impaired, including those blind from birth, claim to see during their NDE OBEs (Moody \& Perry, 1988 , p. 171; St. Claire, 1997, p. 127), and, in a few cases, visuallybased knowledge that could not have been obtained by ordinary means 
can be corroborated independently (Ring \& Cooper, 1997). NDErs who are middle-aged or older may feel or "see" themselves as much younger (Grey, 1985, pp. 87-88; Sabom, 1982, pp. 21-22).

Seventh, the ordinary mental and cognitive faculties of perception, thought, volition, memory, and feelings are present, although sometimes in modified form, as detailed below. There is a heightened sense of reality (Sabom, 1982, pp. 16, 22). There is enhanced clarity of thought, perception, and memory, with lucid mental processes when separated from the body. The NDEr's volition operates without any constraint or limitation of the physical body. The individual can direct movement simply by thinking or desiring it and then move very quickly or seemingly instantaneously (Moody, 1975, pp. 50-52).

Eighth, the individual has visual perception including color, but the perception has much greater acuity than in the body. Vision during the NDE OBE for some experiencers appears still to require light (Ritchie \& Sherrill, 1978, p. 37), but others experience very bright illumination. The NDE OBEr also has a kind of "zooming" or "wraparound" vision involving simultaneous 360 degrees vision around an object, through it, and within it (Benedict, 1996, p. 42; Moody, 1975, pp. 51-52; Ring \& Cooper, 1999, p. 162). The wrap-around vision appears to operate effortlessly. The visual acuity and wrap-around vision may by explained partly by the ability of NDErs to will to focus their attention without the limitations of the physical eyes or the constraint of a particular perspective dictated by the position of the physical body (Moody, 1975, pp. 51-52). The vision during the NDE OBE appears to be a special form of perception, a kind of simultaneous seeing and knowing, which has been termed "mindsight" (Ring \& Cooper, 1999).

Ninth, visual perception also appears to work for objects not visible to ordinary physical sight. NDE OBErs can sometimes see their own nonmaterial "bodies," such as their limbs and clothing, and even describe details of the limbs' structure (Moody \& Perry, 1988, p. 10). The NDEr can see other individuals who are also out of their bodies during the NDE in so-called "group" NDEs (Eulitt \& Hoyer, 2001; Gibson, 1999, pp. 128-130; Moody \& Perry, 1988, p. 173). These fellow NDErs are also "seen" to have a bodily form.

Tenth, individuals can sometimes hear physical sounds such as physical speech, the beeping of monitoring machines, or the hum of fluorescent lights (Ring \& Valarino, 1998, p. 63; Sabom, 1982, p. 100), but many experiencers report not hearing anything in the immediate 
physical environs. Individuals can also "hear" people speak by thought transfer or telepathy (Moody, 1975, pp. 52-53). Some individuals report that they can sense the texture of surfaces of objects by touch, or that they perceive a slight resistance in passing through solid objects (Gabbard \& Twemlow, 1984, p. 158; Moody \& Perry, 1988, p. 9), but in general there is no apparent interaction between the NDEr's "body" and physical objects. The NDEr's "body" appears to be completely nonmaterial. The NDEr cannot be heard when speaking and is invisible to ordinary sight (Moody, 1975, pp. 44-45) but may apparently be sensed by animals (Corcoran, 1996, p. 81).

Eleventh, the process of returning to the physical body can be a gradual return such as walking back or falling back through the tunnel, or a quick snapping back into the body, or simply waking up instantly back in the body. The self-conscious perspective then returns to being fully within the physical body (Moody, 1975, pp. 82-83; Serdahely, 1993, p. 88). The individual's memory of NDE and OBE events is generally very vivid and long-lasting upon returning to the body (van Lommel et al., 2001, pp. 2041-2042).

In the overall gestalt of the NDE OBE, the individual retains all of the perceptual, mental, volitional, emotional, and memory faculties as within the body. However, a number of the faculties are enhanced, apparently as a result of being freed from the physical body. Vision has enhanced acuity with an apparent ability to perceive effortlessly by zooming or from all directions at once, which may be related to the apparent ability of the will to work instantaneously in movement. Thought has an enhanced clarity, and many NDErs appear to hear others by telepathy. There are apparent interactions with some physical processes such as light and sound, and in some cases subtle interaction with solid objects, but in general the NDEr "body" appears to be nonmaterial. When the NDE OBEr returns to the body, the physical characteristics return: weight, fatigue, physical pain, and physical disabilities. The individual's in-body consciousness is restored, and he or she can operate as a physically embodied person again. The will now operates through bodily movement, and the faculties of perception, volition, and thought return to normal. There is continuity of subjective experience throughout the NDE. The individual during the NDE OBE appears to be a complete human being, the same human being as was present prior to the NDE, except for the physical body. The phenomenon of apparent separation of consciousness in the NDE $\mathrm{OBE}$ is a coherent and self-consistent 
experience, which suggests a separation in fact of consciousness from the physical body.

\section{The Self-Conscious Mind}

The OBE component of the NDE includes three basic phenomena that strongly suggest that, during the NDE, the individual's consciousness operates completely independent of the body, with all of its normal cognitive faculties and attributes intact. First, the phenomenon of NDEs during cardiac arrest, which demonstrates a continuity of consciousness, including veridical OBEs, during periods of global cerebral isoelectricity, strongly suggests that consciousness can continue with no electrical brain function. Second, veridical perceptions during NDE OBE, which could have occurred only if consciousness had operated in a location distant from the body, strongly suggest that consciousness can separate from and operate independent of the body. Third, the coherent, self-consistent phenomenology of the NDE OBE suggests that the same human being exists out of the body during the NDE, freed of the constraints and limitations of the body during this time, and exists within the body before and after the NDE.

These three aspects of the NDE OBE, taken together, strongly suggest that human consciousness is an entity in and of itself which, in ordinary life, is united with the brain and body but which may separate from the body during the NDE. We suggest calling this entity the self-conscious mind, a term that Karl Popper and John Eccles (1977) also used, although with a different meaning, as we will describe later. During the NDE OBE, the self-conscious mind operates as an independent, nonmaterial "field of consciousness," that is, there is a particular locus of the experiencer's consciousness and a general spatial organization. "Nonmaterial" here means not consisting of material particles or atoms, and a "field" in this sense is a region of space that has specific properties.

During the NDE OBE, the self-conscious mind is an independent entity. However, during ordinary consciousness in the body, the selfconscious mind is united with the body and brain as an autonomous field of consciousness, spatially coextensive with the body, because consciousness extends throughout the body. While the self-conscious mind is in the body, the brain mediates cognitive faculties, because the brain's normal electrical activity is required for consciousness. The autonomous, nonmaterial self-conscious mind is intimately integrated 
with the body and brain and must, therefore, interact with them in some physical way.

\section{Neurological Phenomena Suggestive of the Self-Conscious Mind}

If this view of the self-conscious mind is correct, then all neurological phenomena in principle should be explainable in terms of such an autonomous agency interacting with the brain. We consider two neurological phenomena and a current prevalent neurological theory of consciousness from this perspective.

\section{Subjective Backward Referral of Sensory Experiences}

In a series of experiments, Libet (1973; Libet, Alberts, Wright, Lewis, \& Feinstein, 1975) showed that electrical activity in the brain must continue about a half second ( 500 milliseconds) before subjects become aware of tactile stimuli. Libet stimulated subjects' skin with a single pulse and measured the electrical brain activity in the region where the stimulated area "projects" to the sensory cortex. Within 10 to 50 milliseconds of the skin stimulus, there is an initial "evoked potential" at the sensory cortex that lasts 15 to 20 milliseconds. The initial evoked potential is followed by a number of "event-related potentials" (ERPs) that represent further neuronal responses in the cortex. The ERPs are broadly distributed across the cortex and typically last for hundreds of milliseconds as a kind of echo of the original stimulus and initial evoked potential. With a stronger skin stimulus, both the evoked potential and ERP amplitudes are larger, and the ERPs continue longer.

Libet found that subjects did not feel the skin stimulus unless it was strong enough to evoke ERPs that lasted at least 500 milliseconds. If the stimulus produced ERPs that lasted only 400 milliseconds, for example, the subjects felt nothing. This result corresponded nicely with the result for direct electrical stimulation of the cortex (Libet, 1973). When an electrode delivers pulses to the cortex, electrical activity similar to the ERPs appears in adjacent cortical regions. If the stimulation lasts at least 500 milliseconds, the subject feels a tingling sensation in the corresponding part of the body. The two phenomena appear to be equivalent. 
Thus, it would appear that human tactile sensory awareness is always delayed by about a half second. But this result seems to contradict experience, because people do not feel as if there is such a relatively long delay in sensations. In a third set of experiments, Libet and colleagues combined the previous experiments, inducing simultaneously both a skin stimulus and direct cortical stimulus to compare the two effects (Libet, Wright, Feinstein, \& Pearl, 1979). They had subjects identify which they felt occurred first: a skin stimulus on one hand or a cortical electrical stimulus projecting to the other hand. If the two stimuli are started precisely at the same time, there should be a 500 millisecond delay in awareness in both cases, and thus the sensations in both hands should be felt as occurring at about the same time. In fact, subjects felt the skin stimulus earlier than the cortical stimulus. If researchers delayed the skin stimulus for some time, even up to 400 milliseconds after the cortical stimulus was started, subjects still felt it to have come earlier. Only when they delayed the skin stimulus more than 500 milliseconds after the cortical stimulus did subjects perceive the skin sensation to occur later than the cortical stimulus.

Thus, subjects appeared to be referring the onset of the skin stimulus back to the time that it actually occurred, even though they did not become consciously aware of the skin sensation, in fact, until a half second after it occurred. Subjects apparently compensated for the built-in sensory delay by subjectively "antedating" it to when the initial evoked potential first appeared in the cortex. With electrical brain stimulation, there is no initial, primary evoked potential in the cortex, and no antedating occurs. Thus, people appear automatically to adjust the sense of when an external stimulus occurs to that moment when the first occurrence of an electrical response to the stimulus appeared, even though this initial evoked potential was subliminal to begin with. The sensation and its timing remain only subliminally "perceived" until at least $\mathbf{5 0 0}$ milliseconds after the stimulus, as if it is in the process of "coming to awareness."

How can this happen? The primary evoked potential is highly localized to the particular region of the primary sensory cortex associated with the particular part of the body that feels the sensation. The later ERPs are not confined to the primary sensory cortex but, rather, are broadly distributed in the cortex. The primary evoked potential serves to provide the signal to both when the sensation occurred and where it occurred in the body. Once the initial evoked potential pulse (lasting only about 20 milliseconds) is gone, all further 
related electrical activity is distributed. There is no apparent electrical neural mechanism that can mediate the subjective backward spatial and temporal referral to the subliminal primary evoked potential (Libet, 2004, pp. 85-86). But there must be some agency to mediate the antedating process: An accurate awareness of the timing and somatic location results from the single primary evoked potential pulse. The referral backward in time is known to occur only when a primary evoked potential is evoked by sensory input (or other stimulation) and can serve as a "time-marker" for the referral. Direct cortical stimulations do not have such a timing signal available, and no backward referral occurs.

Thus, there appears to be an agency that "holds together" both the time and specific sensation (location on the sensory cortex) while the sensation comes to awareness during the 500 millisecond period. No subsequent neural electrical activity can help to place the awareness in the specific sensory location and establish its subjective relative time, so this agency itself cannot be electrical in nature.

\section{Mental Force}

Neural activity can be classified as sensory, motor, or endogenous (internal) mental activity. When people engage in endogenous mental processes (thoughts, imagery, memory recall, attention, and concentration), they sense that their volition is involved. Different types of purely mental thought exercises, such as numerical computation, word recall, and route-finding, were found to involve activation of characteristic, widely separated cortical regions (Roland \& Friberg, 1985). For example, the posterior parietal and right inferior temporal lobes were activated only in the route-finding exercise. Sensory and motor cortical areas were not activated in any of these purely mental exercises. The energy consumption during thinking was equal to or greater than during intense voluntary movement or intense sensory processing. These findings support the subjective impression that endogenous thinking involves mental effort and is different for different kinds of mental activity.

"Plastic" changes in neural structures can occur rapidly when fine motor movements are practiced. In one experiment, after only five twohour sessions, subjects practicing a piano exercise had significantly enlarged cortical areas for the finger muscles involved (Pascual-Leone, Dang, Cohen, Brasil-Neto, Cammarota, \& Hallett, 1995). Enlarged cortical areas were also noted for subjects who only visualized the piano 
exercise but had no actual muscle movement, changes that were nearly as large as with physical practice. After five sessions of only mental practice, subjects were as proficient in actual playing as subjects who had physically practiced for three sessions. These findings suggest that purely endogenous mental effort can result in neural reorganization and physical performance improvement.

Changes in neural patterns were also found in patients treated with cognitive-behavioral therapy for obsessive-compulsive disorder (OCD). Brain imaging of such patients showed a characteristic pattern of neural activity when their symptoms were "provoked," involving neural areas such as anterior cingulate, orbitofrontal, and caudate regions (Breiter, Rauch, Kwong, Baker, Weisskoff, Kennedy, Kendrick, Davis, Jiang, Cohen, Stern, Belliveau, Baer, O'Sullivan, Savage, Jenike, \& Rosen, 1996). These regions appear to form a "locked" neural circuit that is involved in both the obsessive thoughts and the compulsive urges of OCD. The purely mental steps of the behavioral therapy resulted in significant long-lasting reductions in the characteristic OCD neural patterns and in OCD symptoms (Schwartz, 1998). The result of efficacious, long-lasting neural changes from the purely mental effort (attention, concentration, and volition) in OCD therapy led Jeffrey Schwartz (1999) to propose that mental effort generates a "mental force," not reducible to the material, that causes the neural changes.

Indeed, the concept of mental force would apply in all three of these phenomena, wherever endogenous mental effort was felt subjectively, resulting in measurably different brain patterns with different thinking tasks and in measurable neural reorganization with both mental practice and cognitive-behavioral therapy for OCD. Mental effort appears subjectively real, and its appearance corresponds to measurable metabolic energy consumption. Another possible interpretation is that a sense of mental effort is merely an illusion arising from purely neural electrical activity, which exerts "effort" or "force" on itself to produce the measurable effects and reorganization. In contrast, Schwartz's proposed "mental force" is consonant with the subjective sense of the efficacy of volition and mental effort and also suggests that some agency produces the mental force.

\section{Global Workspace Theory}

Global workspace theory is currently the dominant neural model of global brain function (Baars, 1997; Dehaene \& Naccache, 2001) 
accounting for numerous conscious and unconscious processes. Collections of neurons in the brain work together as "modules" to perform various automatic, subconscious functions. Subconscious processes, operating in parallel with limited communication between them, can form coalitions that cooperate to achieve certain goals. "Working memory" is a global process corresponding to what people are conscious of, including inner speech and imagery. The global workspace can be thought of as a theater, where the working memory is the stage on which the spotlight of conscious attention shines. The various actors in the spotlight on stage constitute the content of consciousness, whose information is then distributed globally through the theater to the "audience." Behind the scenes, unconscious processes set the context and "shape" the events on stage. The spotlight of attention shifts dynamically; as a result, widely separated neural modules become dynamically coordinated through long-distance interconnections to produce consciousness. The workspace includes an executive function, that is, a "spotlight controller" and a "director," both of which operate subconsciously behind the scenes to guide the spotlight and to provide the context of a person's sense of self. Volition and voluntary control operate through subconscious "selection" of a dominant goal among a number of competing goals. The dominant goal comes to consciousness and is acted upon; the action can be vetoed if contrary ideas and goals intervene.

Stanislas Dehaene and Jean-Pierre Changeux (2004) have developed computational models of consciousness that simulate the operation of different neural processors in a global neural workspace. To be mobilized in the conscious workspace, a mental object must (1) be represented as a firing pattern of neurons that is established by neural synaptic connections and weights, neurotransmitter efficiencies, receptor densities, and so on; (2) have sufficient long-distance connections with distributed workspace neurons, particularly in the prefrontal, parietal, and cingulate cortices; and (3) receive amplification from top-down signals that dynamically "mobilize" the mental object, that is, direct the spotlight onto it. Voluntary conscious control of attention results from spontaneous generation of probabilistic activity patterns in workspace neurons, from which is selected the pattern most adequate to the current context.

Although they are powerful concepts with significant explanatory and predictive ability, global workspace theory and derivative models appear to pose problems. Individual neurons and neural structures or 
assemblies are essentially receptive in function: They do not spontaneously initiate action potentials but, rather, respond to electrical activity from connecting neurons or from electrical or magnetic stimulation. Activations from external sensory stimuli easily explain initiation of numerous neural processes resulting in consciousness, but conscious initiation of endogenous mental activity is more difficult to explain. The Dehaene-Changeux model, for example, requires spontaneous random generation of possible patterns from which one is selected by "adequacy" to the current "context." Such processes appear to involve "supraneural" capabilities, such as evaluation of adequacy and awareness of context, beyond those available to purely receptive neural assemblies.

Furthermore, the proposal that volition and voluntary control operate through subconscious "selection" of a dominant goal among competing goals does not fit the deliberate selection and conscious mental effort that are subjectively experienced by OCD patients undergoing cognitivebehavioral therapy. Such patients' deliberate selection of thoughts and actions in refocusing their behavior away from the OCD pattern is hardly a "subconscious selection among competing goals." Rather, it is a very conscious selection and exertion of mental effort against the operation of a dominant, nearly overwhelming "locked" neural circuit (Schwartz, 1998). How can purely receptive neural assemblies organize themselves through subconscious selection to counteract such a dominant pattern in the global workspace? Global workspace theory and the Dehaene-Changeux model do not seem to address this case adequately. Again, some sort of mental force as proposed by Schwartz (1999) appears to be a more appropriate model, with the implication of some kind of nonneural agency that exerts the force.

\section{Phenomenology of the Self-Conscious Mind}

The phenomena of backward referral of sensory experience and efficacious conscious mental effort suggest that an agency is involved with consciousness and transcends neural electrical activity. The idea of a nonneural agency also appears to be useful in overcoming apparent difficulties in the prevalent global workspace theory of consciousness, that is, in explaining volition and voluntary control. Because the phenomena connected with NDE OBEs strongly suggest that consciousness can operate as an agency completely independent of the body and brain, we propose that this nonneural agency is the 
consciousness itself, namely, the self-conscious mind defined above. The following details of the self-conscious mind can be inferred from phenomena associated with it during NDE OBEs.

First, during an OBE, the self-conscious mind carries with it the faculties of awareness, perception, thought, volition, memory, and feelings. Consequently, these faculties must also reside with the selfconscious mind while it is united with the brain. Clearly, the brain mediates all of these faculties: When the brain's normal electrical activity is significantly altered, we become unconscious; damage to different cortical areas results in a loss of perception, paralysis, amnesia, and so on. However, when such physical disabilities are present, NDErs experience a resolution of them during the OBE. Thus, the self-conscious mind is an independent "field of consciousness" while out of the body. Because there is a seamless transition of consciousness in leaving the body and then returning, it is apparent that mediation by the brain does not alter the identity or unity of the self-conscious mind's field of consciousness. The mediation of the brain appears to "dampen" mental faculties that appear to have less clarity and sharpness than in the NDE OBE.

Second, the NDE OBE shows that the self-conscious mind, when it is out of the body, is nonmaterial, because the OBE "body" has no substantial ability to interact with physical objects (for example, easily passing through physical objects) and it is invisible to normal sight. Still, when the self-conscious mind is in the body, it appears to be held there strongly. Most people who experience a medical crisis in which one might expect an NDE to occur experience only loss of consciousness and do not experience an apparent separation of the selfconscious mind from the body. The nonmaterial self-conscious mind is thus ordinarily intimately united or integrated with the body and brain and must, therefore, interact in some way with the brain and body. At some level, this interaction has a physical effect in the neurons. Because people ordinarily are unaware of the operation of their brains, the self-conscious mind must operate unconsciously and automatically within the brain and through the brain; consciousness is always directed outward to the world.

Third, when out of the body, most experiencers see that their nonmaterial "bodies" have shape - with limbs, torso, and so on - much like their ordinary body shapes, whereas others experience their shapes as spherical, about the same size as their physical bodies. After the NDE, experiencers' self-conscious perspectives return to being 
fully within their physical bodies. While within the body, a person feels that the physical body is one's own, and one's sense of self extends throughout all parts of the body. Thus, it appears that the selfconscious mind is integrated with the body, extending throughout the head, torso, and limbs, not just with the brain.

Fourth, from the reports of NDErs who had their NDEs as neonates or pre-linguistic infants, the self-conscious mind apparently already exists in fully developed form during infancy. During the NDE, some infant and child experiencers observed their nonmaterial form to be as large as an adult's. In a number of cases, perception, thought, and memory formation have appeared fully functional during the infant NDE. It appears, then, that the self-conscious mind is not developed during infancy as part of the physical development process but, rather, is substantially or fully developed already at birth. If this view is correct, infants go through numerous learning processes in their first several years, as they grow, not to develop the self-conscious mind in itself, but rather to learn to integrate the self-conscious mind with the brain and body. The interactions the self-conscious mind has with the brain in these learning processes in infancy and early childhood probably also influence the development of the brain structures.

Fifth, during an NDE, memories of events while out of the body are formed and integrated seamlessly with the NDEr's other memories both before and after the NDE. For many NDErs, the memories of the NDEs are more vivid than memories of ordinary events. Further, NDErs report that memories of their lives prior to the NDEs, such as memories of their parents, children, or friends, are accessible for recall during the NDEs. Thus, the processes for memory formation and recall must be equivalent both within the body and out of the body, although memory formation, consolidation, and recall are clearly mediated by a number of brain structures and pathways while in the body (Riedel, Michaeu, Lam, Roloff, Martin, Bridge, de Hoz, Poeschel, McCulloch, \& Morris, 1999).

Sixth, both during an NDE and in ordinary consciousness, the experiencer has a sense of self-conscious awareness. Indeed, the experiencer feels that it is the same self that experiences consciousness before, during, and after the NDE. In the present view, it is the self-conscious mind that provides for this experience of continuity and unity of self-consciousness awareness. The self-conscious mind is the unitary field of an individual's consciousness and the locus of selfconscious awareness, both within the body and out of the body. 
In summary, we propose that all cognitive faculties, that is, selfconscious awareness, perception, thought, volition, memory, and feelings, reside in an autonomous self-conscious mind, a nonmaterial field of consciousness that is ordinarily united intimately with the brain and body. Ordinarily, the brain mediates cognitive faculties with the self-conscious mind, which enables a person to be conscious while in the body. Although this self-conscious mind is nonmaterial, the mediation must work through some sort of physical interaction with the brain. The nonmaterial self-conscious mind has a shape or form that extends throughout the physical body. When united with the body, the self-conscious mind must conform to the physical limitations of the body, including disabilities of the body. The self-conscious mind appears to start out in infancy as a fully developed entity; the infant's and child's learning process then involves learning to integrate the self-conscious mind with the brain and body. The processes of memory formation and recall can operate in the self-conscious mind completely independent of the brain. Finally, the autonomous self-conscious mind is the seat of self-conscious awareness. Only during extraordinary events such as NDEs does it separate from the physical body and operate for a time independent of it.

\section{Comparison with Other Theories}

A number of authors have proposed mind-body theories similar to the one we are proposing. Kenneth Arnette's $(1992,1995,1999)$ theory of essence is probably the closest. Arnette argued for the essence-mind as a body of energy from similar grounds of evidence from NDEs, including veridical OBE perceptions, nonmateriality of the OBE body, clarity of thought, telepathic communication, and attraction and interaction between the essence-mind and the physical brain and body. He also argued from cosmological theories, for example, invoking wormholes to explain the tunnel experience. Arnette proposed that mind-brain interaction occurs through a binding of electromagnetic fields, analogous to electric dipole-dipole attraction, which allows a reciprocal causal influence between essence and brain. Whereas we agree with much of Arnette's argument for the essence, we do not propose a particular mechanism for physical mind-brain interaction.

In the dualist interactionist model of Karl Popper and John Eccles (Eccles, 1994: Popper \& Eccles, 1977), the nonmaterial self-conscious mind interacts with a "liaison" portion of the brain located in the 
ideational and linguistic structures of the dominant hemisphere, with a specific mechanism for mind-brain interaction through unitary mental events called "psychons" that operate by means of quantum probability fields. Memory storage is accomplished by imprinting in the brain through modification of synapses, in a kind of data bank, and recall occurs through the replay of spatiotemporal patterns in the brain. Although superficially similar to our view, the Popper-Eccles model is quite different: The latter theorists hold, for example, that the self-conscious mind arises from the brain's activity and is connected with only certain regions of the brain and that memories are stored within brain structures.

Libet (2004) proposed a model of the conscious mental field in which conscious subjective experience is a field produced by the neuronal activity of the brain. The conscious mental field is the mediator between physical neural activity and the emergence of subjective experience. Libet's view was motivated by the phenomenon of the unity of subjective conscious experience and the phenomenon that conscious mental function appears to influence nerve cell activity. In our view, we also consider the self-conscious mind as a field that provides the subjective experience of unity and the agency for neural activation in volitional acts, but we consider the self-conscious mind a nonmaterial entity in itself that can operate independent of the brain.

\section{Mind-Brain Interaction}

How can a nonmaterial mind interact with the physical brain when it seemingly does not interact with other physical things while out of the body? The NDEr's "body" (that is, the self-conscious mind) indeed appears to be nonmaterial and does not appear to interact with objects because it passes easily through them. The NDEr cannot be heard when speaking and is invisible to ordinary sight. However, subtle interactions in different modalities appear to occur with physical substances and energies and with in-body people.

First, the NDEr "body" itself is a "thing" generally having a spatial form and properties. The NDEr "body" appears luminous in some way to the NDEr, that is, giving off some kind of light of its own. Although the "body" cannot be seen by ordinary people, it apparently may be sensed by animals (Corcoran, 1996, p. 81). In at least some NDErs, the "body" appears to have an intricate, luminous structure (Moody \& Perry, 1988, p. 10). The NDEr can touch his "body" and feel it (Ring, 
1980 , p. 52). The NDEr can see other individuals who are also out-ofthe-body during the NDE (Eulitt \& Hoyer, 2001; Gibson, 1999, p. 128; Moody \& Perry, 1988, p. 173). These fellow NDErs also appear to have a bodily form.

Second, the NDEr "body" appears to interact with physical energies. The NDEr's "sight" interacts with light to provide veridical perceptions with normal colors. For some NDErs, visual perception is dependent on the ambient light (Ritchie \& Sherrill, 1978, p. 37). The NDEr's "hearing" interacts with sound vibrations from heart monitors, fluorescent lights, and human speech to provide veridical auditory perceptions.

Third, the NDEr "body" appears to have subtle interaction with solid objects. Some NDErs report a slight resistance in passing through objects, the ability to "bob" against the surface of the ceiling or feel the support of the hospital roof, and the ability to "touch" and feel an object or to have a subtle interaction with a physical object (Blackmore, 1982, p. 52; Corcoran, 1996, p. 80; Fenwick \& Fenwick, 1995, p. 180; Gabbard \& Twemlow, 1984, p. 158).

Fourth, some NDErs appear to have a very strong experience of their "bodies," including the senses of touch, smell, and taste. Howard Storm's NDE included many typical OBE elements (Storm, 2000, pp. 13-15): seeing his physical body in bed and experiencing mental alertness, visual and auditory acuity, the room lit with bright light, and the inability to be seen or heard by those nearby, even with vigorous shouting. Still, Storm did not experience floating above his body but was standing on the floor. He experienced the slickness and coolness of the floor, acutely smelled the odors of the hospital room, acutely heard his own "breathing" and the "rush" of blood in his ears, felt the air moving over his skin, and felt and tasted a stale dryness in his mouth. He could touch his "body," pinched it, and felt pain. The extreme clarity of all of his senses was overpowering and overwhelming. The unusual nature of Storm's NDE OBE may be related to its being a "hellish" NDE at the beginning.

Fifth, in some cases the NDEr "body" appears to interact with another person's physical body. When a cardiac arrest patient passed her hand through Moody's arm, she felt it had a "very rarefied gelatin" consistency, with an electric current running through it (Moody \& Perry, 1988, pp. 8-9). In other cases, the interaction can be felt subtly by the other person: the NDEr playfully tickled another patient's nose until the latter sneezed (Corcoran, 1996, p. 83; see also Cook, Greyson, \& Stevenson, 1998, p. 399). 
Sixth, in some cases the NDEr's "body" appears to "merge" with another person's physical body. During an NDE, a 5-year-old boy who was suffering from meningitis briefly "went into" his sister's head and saw the world through her eyes (Morse \& Perry, 1990, p. 177). In "merging," the NDEr apparently can see and hear and can also communicate information to the person. A 48-year-old man was despondent and attempted suicide by hanging. During his NDE OBE he desperately sought help from his wife. She could not hear his cries, so he "went into" her body and could see and hear with her eyes and ears. When he made contact with her, he heard her exclaim, "Oh, my God!" Apparently she knew what was needed, because she grabbed a knife, ran out to where the man was hanging, and cut him down (Greyson \& Bush, 1992, p. 105).

Such accounts of interaction need to be compiled and analyzed in more detail. The present accounts suggest that there are subtle interactions between the NDEr's "body" and physical reality. Interaction with electromagnetic radiation is suggested by veridical visual perception, including color, which depends on ambient light. Interaction with sound vibrations is suggested by veridical auditory perception of machines beeping, lights humming, and human speech. Interaction with molecular structures is suggested by taste and olfactory perceptions, at least in one case. Interaction with solid matter is suggested by subtle interactions with objects, including feeling a slight resistance when penetrating a ceiling, feeling a rarefied consistency when penetrating a physical arm (at least in one case), and touching a surface and perceiving the qualities of smoothness and coolness (also at least in one case). Interaction with neural electrical activity is suggested by the feeling of electricity when penetrating another person's arm (again, at least in one case), and from visual and auditory perception occurring when the NDEr merged with another person's body. Interaction that influences neural electrical activity is suggested by the ability to tickle an in-body person and the ability to "communicate" in some way when the NDEr merged with another person's body (at least in one case).

Taken together, these accounts strongly suggest that subtle interactions with physical energies, objects, and neural activity can occur and, in particular, that interaction with and influence over neural activity in the brain is possible. The cases of "merging" with another person's body suggest that the out-of-body self-conscious mind readily joins and interacts with the brain, even one from another person. 


\section{Interaction as Interface between Mind and Brain}

How does the self-conscious mind interact with the brain? Our view is that the field of the self-conscious mind merges with the brain and nervous system and works through neural activity. Mind-brain interaction occurs through a global interface between the selfconscious mind and the brain, with three main functions: (1) neural electrical activity of a certain duration and intensity brings sensations and thoughts to consciousness in the self-conscious mind; (2) attentional and volitional mental events originating in the selfconscious mind cause appropriate neural electrical activity to effect motor movements; and (3) neural electrical activity, primarily hippocampal, causes the formation of long-term memories in the self-conscious mind and the "re-call" of memories from the selfconscious mind back to consciousness.

One way to study mind-brain interaction is to analyze specific functions to determine what part of the function is embodied in brain structures and what part is actually "embodied" in the self-conscious mind. Memory is a good example, because memory formation, consolidation, and recall are clearly dependent on certain brain structures and pathways while in the body. Because existing longterm memories are accessible during the $\mathrm{OBE}$, memory content must be "stored" somehow in the nonmaterial self-conscious mind rather than in physiological brain structures. Because new memories can be formed and existing ones recalled during the $\mathrm{OBE}$, memory formation and recall are also functions of the self-conscious mind that are mediated by hippocampal structures while the mind is in the body. Thus, cerebral memory functions would be better considered as neural processes that interface with the self-conscious mind to support formation and recall of memories rather than the storage of memory content.

For example, increase in the size of the right posterior hippocampus in London taxi drivers (Maguire, Gadian, Johnsrude, Good, Ashburner, Frackowiak, \& Frith, 2000) is more likely due to improved spatial recall ability than to storage of spatial representations. Likewise, profound retrograde amnesia (loss of long-term memory), such as in dementia, is probably due to the destruction of brain structures that mediate memory recall rather than destruction of memory content itself (see also Bergson, 1912). According to our model, acquired memories in dementia patients would not be destroyed with the deterioration of cortical structures but would 
return when even a slight reversal of cortical deterioration occurred. Indeed, day-to-day fluctuation of cognitive abilities, including longterm memory recall, is characteristic of neurodegenerative disorders such as Alzheimer's disease (Palop, Chin, \& Mucke, 2006). Rather than lose the past, people with Alzheimer's disease gradually become blind to it.

Another way to study mind-brain interaction is through the cytoarchitecture of different cortical areas (Brodmann, 2006/1909). Each Brodmann area has a different layered cytoarchitecture that potentially represents a different type of interface with the selfconscious mind. If the self-conscious mind interacts with and alters electrical brain processes, there must be some sort of "mental force" (Schwartz, 1999) that the self-conscious mind exerts to bring about this interaction. In attentional and volitional functions, the dendritic branching structure in lamina $I$, the outermost cortical layer, may provide the primary interface where the self-conscious mind can exert "force" to influence neural activity.

In this regard, we suggest that the global workspace theory be extended to include the role of the self-conscious mind in consciousness. That is, the self-conscious mind can be added as an element to global workspace models as the location of both conscious and subliminal mental content and the origin of volitional activity. In the theater model, the self-conscious mind becomes the stage, the contexts, and the director. Nevertheless, the mechanics of the theater operation through neural modules and long-distance interconnectivity is still essential for consciousness to occur within the self-conscious mind: In the theater analogy, without the lighting (neural activity), the stage is still dark (unconsciousness).

We would expect the processes of mind-brain interaction, having evolved over millennia, to be perfectly "tuned" for efficiency, and we would expect brain-to-mind and mind-to-brain interactions to be complementary or symmetrical to one another, perhaps similar to the way that electric and magnetic fields are mutually inductive. The specific mechanisms for mind-brain interaction are open for investigation. A number of mechanisms have already been proposed, for example: quantum mechanical neurophysical interaction (Schwartz, Stapp, \& Beauregard, 2005), orchestrated objective reduction process in neuron microtubules (Hameroff, 2007; Hameroff \& Penrose, 2003), binding of electromagnetic fields (Arnette, 1999), and fields of consciousness in phase space (van Lommel, 2006). 


\section{Application to Neurological Phenomena}

In principle, all neurological phenomena should be explainable in terms of the autonomous self-conscious mind interacting with the brain. We present one such phenomenon in detail and suggest an avenue of further study for another.

\section{Libet's Delayed Awareness of Willed Action}

Libet conducted a series of experiments to time the relationship between the subjective sense of willing to move and the actual movement. He told subjects to flex their wrists at a time freely chosen (Libet, 1985; Libet, Gleason, Wright, \& Pearl, 1983). The neural response to a subjective command to move is measured at the top of the head and is called a "readiness potential." Prior to any motor activity, the readiness potential appears as a slow rise in electrical negativity measured at the scalp at the top of the head and is thought to indicate a preparation for the movement. In these experiments, Libet found that the readiness potential neural response typically started 550 milliseconds before the actual muscle movement measured at the wrist by an electromyogram.

In one series of timings, Libet asked subjects to note the time they first became aware that they actually moved. This time was measured by reporting the position of a rotating spot of light on an oscilloscope, one rotation occurring every 2.56 seconds. Subjects noted the position of the spot on the circular "clock" when they first became aware of moving their wrists. The accuracy of these timings was confirmed by other tests to be within $\mathbf{5 0}$ milliseconds. The subjects reported their first awareness of moving $(\mathrm{M})$ to be about 85 milliseconds prior to the actual muscle movement (EMG).

In a separate series of timings, subjects were asked to note the time they first became aware of wanting to move. Ironically, the subject's first awareness of the intention or wish to move (W) was about 200 milliseconds prior to the actual muscle movement - that is, on average 350 milliseconds after the onset of the readiness potential. This delay makes it appear that the brain has decided to move prior to the subject's actual conscious intention to move.

The apparent "decision" by the brain to act prior to the actual awareness of the intention to act is counterintuitive and implies that people do not act out of free will even when they subjectively feel that 
they do. However, if one accepts the proposition that people's awareness of their own endogenous mental acts is delayed in the same way as awareness of tactile sensations, Libet's results become less enigmatic.

In a separate series of experiments, Libet found that a minimum duration ("time-on") of neural activity of about a half second is required to elicit conscious sensory experience (Libet, Pearl, Morledge, Gleason, Hosobuchi, \& Barbaro, 1991). If the neural activity is less than that duration, the sensation is detected subliminally but with no awareness. Libet $(2004$, p. 106) concluded that awareness is a phenomenon independent of content and that such minimum durations are a unique requirement for awareness. People can detect stimuli and are thus able to react quickly in emergencies and in physical activities requiring a high degree of responsiveness and accuracy, as in the case of skilled musicians or tennis players. These reactions usually occur within 100 to 150 milliseconds; only after a somewhat longer delay do people become aware of the stimuli.

We propose that all mental events, including endogenous events such as the wish or intention to act, begin subconsciously and have a similar time-on requirement. This proposition is similar to Libet's own proposal (1993, p. 385). In the willed action experiment, the awareness of moving, $M$, occurs about 465 milliseconds after the onset of the readiness potential, $R P$. Thus, the readiness potential may also serve as the neural time-on requirement for awareness of movement. Similarly, we propose that the subconscious wish or intention to move, $W$, requires a time-on of about 500 milliseconds before the awareness of the wish to move and, thus, occurs some 150 milliseconds prior to the onset of the readiness potential. The relative times of events from Libet's experiments would thus be as follows:

- -700 msec: subconscious wish to move (proposed)

- -550 msec: readiness potential begins (RP)

- -200 msec: awareness of wish to move (W)

- -85 msec: awareness of moving (M)

- 0 msec: muscle movement (EMG)

But how can people subconsciously intend to do something and then a half second later become aware of the intention? In our view, a freewill decision originates in the conscious agency of the self-conscious mind, but the neural activity reflecting this mental act must meet the 500 -millisecond time-on requirement before there can be awareness of 
the decision. This explanation is consistent with people's subjective experience that their decisions are purely their own and arise from the conscious context they are in: They would be very surprised to find that they have decided something contrary to that context. Endogenous mental activity must work through the brain's neural activity in order to reach awareness. In contrast, when the self-conscious mind is free of the body, as in an NDE OBE, endogenous mental activity appears to have a different character. For example, will appears to work "instantly"; that is, as soon as someone wishes something, it appears to be fulfilled, unencumbered by the brain or body. The timeon delay of awareness of endogenous mental acts thus helps explain the apparent disconnect between volition and action, such as William James's (1890) introspection of the process of getting out of bed on a freezing morning and Libet's apparent contradiction that the brain "decides" before the person is aware of deciding.

\section{Phantom Limbs}

A phantom limb is the vivid subjective experience that a limb that is congenitally absent or has been amputated is still present (Ramachandran \& Hirstein, 1998). In the present view, the self-conscious mind is a spatially-extended field that is coextensive with the physical body, probably interacting with the limbs by way of the peripheral afferent and efferent nerves. In the absence of a physical limb, a part of the self-conscious mind would still project beyond the stump as a kind of "mind limb" extending beyond the physical body. Some of the subjective sensations associated with the phantom could thus be due to the interaction of its "mind limb" with the physical body.

Thus, from our model, we would expect the spatial region of the phantom limb extending beyond the stump to exhibit some of the properties of the independent OBE "body." These might include, for example, (1) subtle interaction when a physical object enters the spatial region of the phantom, possibly causing physical sensations within the body; (2) subtle interaction of the phantom limb with another person's physical body, which could be felt by the other person; and (3) a faint glowing of the phantom in the dark, much like the reports by some NDErs of seeing their own out-of-body form. These properties are speculative and may not prove to be present, because unlike the independent OBE "body," the phantom "mind limb" still has a connection to and interaction with the physical body and brain. 
Likewise, the possible glowing of a phantom would probably not be electromagnetic radiation and would be observable only through some extrasensory faculty. Interestingly, one phantom limb subject, a 44year-old university-educated woman born without forearms and without legs, a condition known as congenital tetramelia, stated, "In darkness, I have noted a faint glowing of my phantom body parts" (Brugger, Kollias, Müri, Crelier, Hepp-Reymond, \& Regard, 2000).

\section{Conclusion}

We have used phenomenological investigation (Zajonc, 1999) to define the self-conscious mind. We characterize the self-conscious mind as a nonmaterial "field of consciousness" that nonetheless has subtle physical interactions at some level with the brain, because the phenomena of the NDE OBE lead us to that conclusion. In order to function in the body, the self-conscious mind must be acted upon by neural electrical activity and, in turn, must exert a "mental force" on neurons, causing a physical effect. The self-conscious mind does not appear to be a subtle "substance" because it appears to be unitary and indivisible. Although it has extension and location in space, the selfconscious mind readily interpenetrates ordinary matter and, thus, is not material in any ordinary sense. Rather than a subtle substance, the self-conscious mind appears to be more the seat of the essential selfhood of the person.

\section{References}

Ames, A., Wright, R. L., Kowada, M., Thurston, J. M., and Majno, G. (1968). Cerebral ischemia. II. The no-reflow phenomenon. American Journal of Pathology, 52, 437-453.

Aminoff, M. J., Scheinman, M. M., Griffin, J. C., and Herre, J. M. (1988). Electrocerebral accompaniments of syncope associated with malignant ventricular arrhythmias. Annals of Internal Medicine, 108, 791-796.

Arnette, J. K. (1992). On the mind/body problem: The theory of essence. Journal of NearDeath Studies, 11, 5-18.

Arnette, J. K. (1995). The theory of essence. II. An electromagnetic-quantum mechanical model of interactionism. Journal of Near-Death Studies, 14, 77-99.

Arnette, J. K. (1999). The theory of essence. III: Neuroanatomical and neurophysiological aspects of interactionism. Journal of Near-Death Studies, 18, 73-101.

Atwater, P. M. H. (1994). Beyond the light: What isn't being said about the near-death experiences. New York: Birch Lane.

Atwater, P. M. H. (2003). The new children and near-death experiences. Rochester, VT: Bear. 
Atwater, P. M. H. (2007). The big book of near-death experiences: The ultimate guide to what happens when we die. Charlottesville, VA: Hampton Roads.

Augustine, K. (2007a). Does paranormal perception occur in near-death experiences? Journal of Near-Death Studies, 25, 203-236.

Augustine, K. (2007b). "Does paranormal perception occur in near-death experiences?" defended. Journal of Near-Death Studies, 25, 261-283.

Baars, B. J. (1997). In the theater of consciousness: The workspace of the mind. New York: Oxford University Press.

Benedict, M.-T. (1996). Through the light and beyond. In L. W. Bailey and J. Yates (eds.), The near-death experience: A reader (pp. 39-52). New York: Routledge.

Bergson, H. (1912). Matter and memory (trans. by N. M. Paul \& W. S. Palmer). New York: Macmillan, (Original work published in French as Matière et mémoire)

Blackmore, S. (1982). Beyond the body: An investigation of out-of-the-body experiences. London: Heinemann.

Blackmore, S. (1993). Dying to live: Near-death experiences. Buffalo, NY: Prometheus.

Breiter, H. C., Rauch, S. L., Kwong, K. K., Baker, J. R., Weisskoff, R. M., Kennedy, D. N., Kendrick, A. D., Davis, T. L., Jiang, A., Cohen, M. S., Stern, C. E., Belliveau, J. W., Baer, L., O'Sullivan, R. L., Savage, C. R., Jenike, M. A., and Rosen, B. R. (1996). Functional magnetic resonance imaging of symptom provocation in obsessivecompulsive disorder. Archives of General Psychiatry, 53, 595-606.

Brenner, R. P. (1997). Electroencephalography in syncope. Journal of Clinical Neurophysiology, 14, 197-209.

Brodmann, K. (2006). Localisation in the cerebral cortex: The principles of comparative localisation in the cerebral cortex based on cytoarchitectonics. New York: Springer, (Originally published in German in 1909)

Brown, A. S. (2004). The déjà vu experience. New York: Psychology Press.

Brugger, P., Kollias, S. S., Müri, R. M., Crelier, G., Hepp-Reymond, M.-C., and Regard, M. (2000). Beyond re-membering: Phantom sensations of congenitally absent limbs. Proceedings of the National Academy of Sciences of the United States of America, 97, 6167-6172.

Buunk, G., van der Hoeven, J. G., and Meinders, A. E. (2000). Cerebral blood flow after cardiac arrest. The Netherlands Journal of Medicine, 57, 106-112.

Clute, H. L., and Levy, W. J. (1990). Electroencephalographic changes during brief cardiac arrest in humans. Anesthesiology, 73, 821-825.

Cook, E. W., Greyson, B., and Stevenson, I. (1998). Do any near-death experiences provide evidence for the survival of human personality after death? Relevant features and illustrative case reports. Journal of Scientific Exploration, 12, 377-406.

Corcoran, D. K. (ed.). (1996). When ego dies: A compilation of near-death and mystical conversion experiences. Houston, TX: Emerald Ink.

de Vries, J. W., Bakker, P. F. A., Visser, G. H., Diephuis, J. C., and van Huffelen, A. C. (1998). Changes in cerebral oxygen uptake and cerebral electrical activity during defibrillation threshold testing. Anesthesia and Analgesia, 87, 16-20.

de Vries, J. W., Visser, G. H., and Bakker, P. F. A. (1997). Neuromonitoring in defibrillation threshold testing: A comparison between EEG, near-infrared spectroscopy and jugular bulb oximetry. Journal of Clinical Monitoring, 13, 303-307.

Dehaene, S., and Changeux, J.-P. (2004). Neural mechanisms for access to consciousness. In M. S. Gazzaniga (ed.), The cognitive neurosciences III ( $3^{\text {rd }}$ ed.; pp. 1145-1157). Cambridge, MA: Massachusetts Institute of Technology Press.

Dehaene, S., and Naccache, L. (2001). Towards a cognitive neuroscience of consciousness: Basic evidence and a workspace framework. Cognition, 79, 1-37.

Dougherty, C. M. (1994). Longitudinal recovery following sudden cardiac arrest and internal cardioverter defibrillator implantation: Survivors and their families. American Journal of Critical Care, 3, 145-154.

Dovel, M. D. (2003). My last breath. Baltimore: PublishAmerica. 
Eccles, J. C. (1994). How the self controls its brain. Berlin, Germany: Springer-Verlag. Edwards, P. (1996). Reincarnation: A critical examination. Amherst, NY: Prometheus.

Eulitt, M., and Hoyer, S. (2001). Fireweaver: The story of a life, a near-death, and beyond. Philadelphia: Xlibris.

Fenwick, P., and Fenwick, E. (1995). The truth in the light: An investigation of over 300 near-death experiences. New York: Berkley Books.

Fujioka, M., Nishio, K., Miyamoto, S., Hiramatsu, K. I., Sakaki, T., Okuchi, K., Taoka, T., and Fujioka, S. (2000). Hippocampal damage in the human brain after cardiac arrest. Cerebrovascular Diseases, 10, 2-7.

Gabbard, G. O., and Twemlow, S. W. (1984). With the eyes of the mind: An empirical analysis of out-of-body states. New York: Praeger.

Gibson, A. S. (1992). Glimpses of eternity: New near-death experiences examined. Bountiful, UT: Horizon.

Gibson, A. S. (1999). Fingerprints of God: Evidences from near-death studies, scientific research on creation, and Mormon theology. Bountiful, UT: Horizon.

Gopalan, K. T., Lee, J., Ikeda, S., and Burch, C. M. (1999). Cerebral blood flow velocity during repeatedly induced ventricular fibrillation. Journal of Clinical Anesthesia, 11, 290-295.

Grey, M. (1985). Return from death: An exploration of the near-death experience. London: Arkana.

Greyson, B. (1983). The Near-Death Experience Scale: Construction, reliability, and validity. Journal of Nervous and Mental Disease, 171, 369-375.

Greyson, B. (2003). Incidence and correlates of near-death experiences in a cardiac care unit. General Hospital Psychiatry, 25, 269-276.

Greyson, B., and Bush, N. E. (1992). Distressing near-death experiences. Psychiatry, 55 , 95-110.

Greyson, B., and Stevenson, I. (1980). The phenomenology of near-death experiences. American Journal of Psychiatry, 137, 1193-1196.

Hameroff, S. (2007). Orchestrated reduction of quantum coherence in brain microtubules: A model for consciousness. NeuroQuantology, 5, 1-8.

Hameroff, S., and Penrose, R. (2003). Conscious events as orchestrated space-time selections. NeuroQuantology, 1, 10-35.

Harris, B., and Bascom, L. C. (1990). Full circle: The near-death experience and beyond. New York: Simon and Schuster.

Herlitz, J., Bång, A., Aune, S., Ekström, L., Lundström, G., and Holmberg, S. (2001). Characteristics and outcome among patients suffering in-hospital cardiac arrest in monitored and non-monitored areas. Resuscitation, 48, 125-135.

Holden, J. M. (2008). Veridical perceptions in near-death experiences. In J. M. Holden, B. Greyson, and D. James (eds.), Near-death experiences: Thirty years of scholarly inquiry. Westport, CT: Greenwood/Praeger.

James, W. (1890). The principles of psychology. New York: Henry Holt.

Kågström, E., Smith, D. L., and Siesjö, B. K. (1983). Local cerebral blood flow in the recovery period following complete cerebral ischemia in the rat. Journal of Cerebral Blood Flow and Metabolism, 3, 170-182.

Kinney, H. C., Korein, J., Panigrahy, A., Kikkes, P., and Goode, R. (1994). Neuropathological findings in the brain of Karen Ann Quinlan. New England Journal of Medicine, 330, 1469-1475.

Lawrence, M. (1997). In a world of their own: Experiencing unconsciousness. Westport, CT: Praeger.

Libet, B. (1973). Electrical stimulation of cortex in human subjects, and conscious sensory aspects. In A. Iggo (ed.), Handbook of sensory physiology, volume II: Somatosensory system (pp. 743-790). Berlin, Germany: Springer-Verlag.

Libet, B. (1985). Unconscious cerebral initiative and the role of conscious will in voluntary action. Behavioral and Brain Sciences, 8, 529-566. 
Libet, B. (1993). Neurophysiology of consciousness: Selected papers and new essays. Boston: Birkhäuser.

Libet, B. (2004). Mind time: The temporal factor in consciousness. Cambridge, MA: Harvard University Press.

Libet, B., Alberts, W. W., Wright, E. W., Lewis, M., and Feinstein, B. (1975). Cortical representation of evoked potentials relative to conscious sensory responses, and of somatosensory qualities - in man. In H. H. Kornhuber (ed.), The somatosensory system (pp. 291-308). Acton, MA: Publishing Sciences Group.

Libet, B., Gleason, C. A., Wright, E. W., and Pearl, D. K. (1983). Time of conscious intention to act in relation to onset of cerebral activity (readiness-potential): The unconscious initiation of a freely voluntary act. Brain, 106, 623-642.

Libet, B., Pearl, D. K., Morledge, D. E., Gleason, C. A., Hosobuchi, Y., and Barbaro, N. M. (1991). Control of the transition from sensory detection to sensory awareness in man by the duration of a thalamic stimulus: The cerebral "time-on" factor. Brain, 114, 1731-1757.

Libet, B., Wright, E. W., Feinstein, B., and Pearl, D. K. (1979). Subjective referral of the timing for a conscious sensory experience: A functional role for the somatosensory specific projection system in man. Brain, 102, 193-224.

Losasso, T. J., Muzzi, D. A., Meyer, F. B., and Sharbrough, F. W. (1992). Electroencephalographic monitoring of cerebral function during asystole and successful cardiopulmonary resuscitation. Anesthesia and Analgesia, 75, 1021-1024.

Lundahl, C. R., and Widdison, H. A. (1997). The eternal journey: How near-death experiences illuminate our earthly lives. New York: Warner.

Maguire, E. A., Gadian, D. G., Johnsrude, I. S., Good, C. D., Ashburner, J., Frackowiak, R. S. J., and Frith, C. D. (2000). Navigation-related structural change in the hippocampi of taxi drivers. Proceedings of the National Academy of Sciences of the United States of America, 97, 4398-4403.

Moody, Jr., R. A (1975). Life after life. Covington, GA: Mockingbird Books.

Moody, Jr., R. A., and Perry, P. (1988). The light beyond. New York: Bantam Books.

Morse, M., and Perry, P. (1990). Closer to the light: Learning from the near-death experiences of children. New York: Villard.

Osterman, J. E., Hopper, J., Heran, W. J., Keane, T. M., and van der Kolk, B. A. (2001). Awareness under anesthesia and the development of posttraumatic stress disorder. General Hospital Psychiatry, 23, 198-204.

Palop, J. J., Chin, J., and Mucke, L. (2006). A network dysfunction perspective on neurodegenerative diseases. Nature, 443, 768-773.

Parnia, S. (2006). What happens when we die? A groundbreaking study into the nature of life and death. Carlsbad, CA: Hay House.

Parnia, S., and Fenwick, P. (2002). Near-death experiences in cardiac arrest: Visions of a dying brain or visions of a new science of consciousness. Resuscitation, 52, 5-11.

Parnia, S., Waller, D. G., Yeates, R., and Fenwick, P. (2001). A qualitative and quantitative study of the incidence, features and aetiology of near-death experiences in cardiac arrest survivors. Resuscitation, 48, 149-156.

Pascual-Leone, A., Dang, N., Cohen, L. G., Brasil-Neto, J. P., Cammarota, A., and Hallett, M. (1995). Modulation of muscle responses evoked by transcranial magnetic stimulation during the acquisition of new fine motor skills. Journal of Neurophysiology, 74, 1037-1045.

Popper, K. R., and Eccles, J. C. (1977). The self and its brain: An argument for interactionism. London: Routledge.

Ramachandran, V. S., and Hirstein, W. (1998). The perception of phantom limbs: The D. O. Hebb lecture. Brain, 121, 1603-1630.

Riedel, G., Michaeu, J., Lam, A. G. M., Roloff, E. v. L., Martin, S. J., Bridge, H., de Hoz, L., Poeschel, B., McCulloch, J., and Morris, R. G. M. (1999). Reversible neural inactivation reveals hippocampal participation in several memory processes. Nature Neuroscience, 2, 898-905. 
Ring, K. (1980). Life at death: A scientific investigation of the near-death experience. New York: Coward, McCann and Geoghegan.

Ring, K., and Cooper, S. (1997). Near-death and out-of-body experiences in the blind: A study of apparent eyeless vision. Journal of Near-Death Studies, 16, 101-147.

Ring, K., and Cooper, S. (1999). Mindsight: Near-death and out-of-body experiences in the blind. Palo Alto, CA: William James Center for Consciousness Studies.

Ring, K., and Valarino, E. E. (1998). Lessons from the light: What we can learn from the near-death experience. New York: Plenum/Insight.

Ritchie, G. G. (1998). Ordered to return: My life after dying. Charlottesville, VA: Hampton Roads.

Ritchie, G. G., and Sherrill, E. (1978). Return from tomorrow. Waco, TX: Chosen Books.

Roland, P. E., and Friberg, L. (1985). Localization of cortical areas activated by thinking. Journal of Neurophysiology, 53, 1219-1243.

Sabom, M. B. (1982). Recollections of death: A medical investigation. New York: Harper and Row.

Sabom, M. B. (1998). Light at death: One doctor's fascinating account of near-death experiences. Grand Rapids, MI: Zondervan.

Sabom, M. B. (2007). Commentary on "Does paranormal perception occur in near-death experiences?" Journal of Near-Death Studies, 25, 257-260.

St. Clair, M. (1997). Beyond the light: Files of near-death experiences. New York: Barnes and Noble.

Sartori, P., Badham, P., and Fenwick, P. (2006). A prospectively studied near-death experience with corroborated out-of-body perceptions and unexplained healing. Journal of Near-Death Studies, 25, 69-84.

Sauvé, M. J., Walker, J. A., Massa, S. M., Winkle, R. A., and Scheinman, M. M. (1996). Patterns of cognitive recovery in sudden cardiac arrest survivors: The pilot study. Heart and Lung, 25, 172-181.

Schwaninger, J., Eisenberg, P. R., Schechtman, K. B., and Weiss, A. N. (2002). A prospective analysis of near-death experiences in cardiac arrest patients. Journal of Near-Death Studies, 20, 215-232.

Schwartz, J. M. (1998). Neuroanatomical aspects of cognitive-behavioural therapy response in obsessive-compulsive disorder: An evolving perspective on brain and behaviour. British Journal of Psychiatry, 173(Suppl. 35), 38-44.

Schwartz, J. M. (1999). A role for volition and attention in the generation of new brain circuitry: Toward a neurobiology of mental force. Journal of Consciousness Studies, 6 , 115-142.

Schwartz, J. M., Stapp, H. P., and Beauregard, M. (2005). Quantum physics in neuroscience and psychology: A neurophysical model of mind-brain interaction. Philosophical Transactions of the Royal Society of London, Series B, 360, 1309-1327.

Serdahely, W. J. (1993). Near-death experiences and dissociation: Two cases. Journal of Near-Death Studies, 12, 85-94.

Serdahely, W. J., and Walker, B. A. (1990). A near-death experience at birth. Death Studies, 14, 177-183.

Smith, D. S., Levy, W., Maris, M., and Chance, B. (1990). Reperfusion hyperoxia in brain after circulatory arrest in humans. Anesthesiology, 73, 12-19.

Spetzler, R. F., Hadley, M. N., Rigamonti, D., Carter, L. P., Raudzens, P. A., Shedd, S. A., and Wilkinson, E. (1988). Aneurysms of the basilar artery treated with circulatory arrest, hypothermia, and barbiturate cerebral protection. Journal of Neurosurgery, 68 , 868-879.

Steiger, B. (1994). One with the light. New York: Penguin.

Storm, H. (2000). My descent into death: And the message of love which brought me back. London: Clairview Books.

Sutherland, C. (1995). Children of the light: The near-death experiences of children. Sydney, Australia: Bantam. 
van Lommel, P. (2006). Near-death experience, consciousness and the brain: A new concept about the continuity of our consciousness based on recent scientific research on near-death experience in survivors of cardiac arrest. World Futures, 62, 134-151. van Lommel, P., van Wees, R., Meyers, V., and Elfferich, I. (2001). Near-death experience in survivors of cardiac arrest: A prospective study in the Netherlands. Lancet, 358, 2039-2045.

Visser, G. H., Wieneke, G. H., van Huffelen, A. C., de Vries, J. W., and Bakker, P. F. A. (2001). The development of spectral EEG changes during short periods of circulatory arrest. Journal of Clinical Neurophysiology, 18, 169-177.

Vriens, E. M., Bakker, P. F. A., de Vries, J. W., Wieneke, G. H., and van Huffelen, A. C. (1996). The impact of repeated short episodes of circulatory arrest on cerebral function. Reassuring electroencephalographic (EEG) findings during defibrillation threshold testing at defibrillator implantation. Electroencephalography and Clinical Neurophysiology, 98, 236-242.

Zajonc, A. (1999). Goethe and the phenomenological investigation of consciousness. In S. R. Hameroff, A. W. Kaszniak, and D. J. Chalmers (eds.), Toward a science of consciousness, III: The third Tucson discussion and debates. Cambridge, MA: Massachusetts Institute of Technology Press. 